\title{
Utility of an Octane/1-Octanol Mixed Solvent for the Determination of Formation and Partition Constants of Ion Associates in the Extraction of Copper(II) with 2-(2-Pyridylazo)-1-naphthol-4- sulfonic Acid and with Tetrabutylammonium Cation
}

\author{
Hiromichi Yamada, Kyoko Teranishi, Hiroshi Niwa, Yoshinori Shigematsu, \\ Tetsuo UchIDA and Hiroko WADA
}

Department of Applied Chemistry, Nagoya Institute of Technology, Gokiso, Showa, Nagoya 466, Japan

\begin{abstract}
The extraction of copper(II) with 2-(2-pyridylazo)-1-naphthol-4-sulfonic acid and tetrabutylammonium ion using the octane/1-octanol mixed solvent was carried out at $25^{\circ} \mathrm{C}$. The formation and partition constants of ion associates formed between tetrabutylammonium ion and 2-(2-pyridylazo)-1-naphthol-4-sulfonate and/or its cuprate(II) anions were determined by an analysis of the extraction equilibria. The utility of the octane/1-octanol mixed solvent for ion association extraction systems can be demonstrated as a lower toxicity solvent than halogenated solvents, such as chloroform, 1,2-dichloroethane etc.
\end{abstract}

Keywords Mixed solvent, ion association constant, partition constant, 2-(2-pyridylazo)-1-naphthol-4-sulfonic acid, copper(II)

A number of investigations on ion association extraction systems have been carried out. In the ion association extraction systems, the extraction is dependent on the formation of an ion associate in the aqueous phase and its partition between the aqueous and organic phases. The extraction constant, which is defined as the product of the ion association constant in the aqueous phase and the partition constant of the ion associate, were investigated in detail by Motomizu et al..$^{1-4}$, Goto et al..$^{5-7}$ and Yotsuyanagi et al. ${ }^{8}$ However, these individual ion association and partition constants are scarcely determined, because it is difficult to determine the ion association constant.

Up to now, halogenated solvents, such as chloroform and 1,2-dichloroethane, have been exclusively used for ion association extraction. From the point of view of preserving the natural environment, these solvents are undesirable for use. These solvents should be controlled regarding their use as much as possible. In previous work concerning the extraction of copper(II) with benzoic acid, 1-octanol/benzene and 1-octanone/ benzene mixed solvents ranging in certain limited compositions were found to be superior to chloroform. ${ }^{9}$

In preliminary experiments on the extraction of copper(II) with 2-(2-pyridylazo)-1-naphthol-4-sulfonic acid and tetrabutylammonium ion, it was found that neat 1-octanol possesses a poor phase-separating ability as a solvent, but good extractability, whereas neat octane has a poor extractabilty but a good phase-separating ability.
Mixture of neat solvents can be expected to have good extractability and good phase-separating ability by compensating for each disadvantage.

In the present work this mixed solvent has been demonstrated to be useful for the present ion association extraction as a lower toxicity solvent than the halogenated solvents and benzene. In addition, the ion association constants of ion associates of 2-(2-pyridylazo)1-naphthol-4-sulfonate and its anionic copper(II) complex with tetrabutylammonium ion in the aqueous phase and their partition constants, which have been scarcely determined so far, have been estimated by an analysis of the partition equilibrium.

\section{Experimental}

\section{Reagents}

2-(2-Pyridylazo)-1-naphthol-4-sulfonic acid ( $\alpha$-PAN4S: $\mathrm{H}_{2} \mathrm{~L}$ ) was synthesized by the method of Anderson and Nickless. ${ }^{10}$ Its purity was confirmed to be more than $97.5 \%$ as a monohydrate. Tetrabutylammonium bromide of specially prepared Analytical Reagent (Tokyo Kasei Kogyo Co., Ltd.) was used as an ion-pairing reagent. Octane of reagent grade was purified by washing successively with concentrated sulfuric acid, dilute sodium hydroxide, dilute perchloric acid solutions and distilled-deionized water. 1-Octanol of reagent grade was purified by a similar method as octane, except 
for using concentrated sulfuric acid. Mixed solvents were prepared by mixing purified octane and 1-octanol in volume ratios of $1: 1,2: 1$ and $3: 1$ just before use. A copper(II) standard solution was prepared by dissolving copper(II) perchlorate hexahydrates (98\%, Aldrich Chemical Company, Inc.) in dilute perchloric acid. All other reagents were of reagent grade and were used without further purification. Aqueous solutions were prepared with distilled-deionized water.

\section{Procedure}

Partition was performed in a thermostatic bath kept at $25^{\circ} \mathrm{C}$. A volume of $10 \mathrm{ml}$ each of aqueous and organic phases was shakén for $30 \mathrm{~min}$, which was sufficient for complete equilibration, in a 50-ml centrifuge tube. The aqueous phase contained a proper amount of $\alpha$-PAN-4S, $\mathrm{TBA}^{+}$and buffer solutions for the partition of $\alpha$-PAN$4 \mathrm{~S}$, and further $1 \times 10^{-5} \mathrm{~mol} \mathrm{dm}^{-3}$ copper(II) for the partition of copper(II). The organic phase is the octane/1octanol mixed solvents in volume ratios of $1: 1,2: 1$ and $3: 1$. The ionic strength in the aqueous phase was not kept constant, because the ions added to control the ionic strength were liable to cause other ion association reactions in the aqueous phase and its partition to the organic phase.

\section{Apparatus}

For determining the concentrations of $\alpha-\mathrm{PAN}-4 \mathrm{~S}$ and copper(II) $\left[\mathrm{CuL}_{2}{ }^{2-}\right]$ were determined spectrophotometrically using a Ubest-55 UV/VIS Spectrophotometer (Jasco, Tokyo). The concentration of copper(II) in the aqueous phase was determined directly, and that in the organic phase was determined after back extraction by a $0.5 \mathrm{~mol} \mathrm{dm}^{-3}$ nitric acid solution using a SAS-727 Atomic Absorption Spectrophotometer (Seiko Instruments Inc., Tokyo). The $\mathrm{pH}$ measurements were carried out with a Horiba pH/Ion Meter F-23 (Horiba Seisakusho Ltd., Kyoto). The water content in $\alpha$-PAN-4S was coulometrically measured using a Karl-Fischer Moisture Titrator MKC-210 (Kyoto Electronics Manufacturing Co., Kyoto). The other apparatus were the same as those used in a previous study" for mechanical shaking and centrifugation.

\section{Results and Discussion}

\section{Partition equilibrium of $\alpha-P A N-4 S$}

Three kinds of the octane/1-octanol mixed solvents in volume ratios of $1: 1,2: 1$, and $3: 1$ were used in the present study.

The partition equilibrium of ion associates of $\mathrm{TBA}^{+}$ and $\alpha$-PAN-4S anion is dependent on the following seven kinds of equilibria.

Acid dissociation of $\alpha-\mathrm{PAN}-4 \mathrm{~S}\left(\mathrm{H}_{2} \mathrm{~L}\right)$ :

$$
\begin{aligned}
& \mathrm{H}_{2} \mathrm{~L} \rightleftharpoons \mathrm{H}^{+}+\mathrm{HL}^{-} ; K_{\mathrm{al}}=\left[\mathrm{H}^{+}\right]\left[\mathrm{HL}^{-}\right] /\left[\mathrm{H}_{2} \mathrm{~L}\right], \\
& \mathrm{HL}^{-} \rightleftharpoons \mathrm{H}^{+}+\mathrm{L}^{2-} ; K_{\mathrm{a2} 2}=\left[\mathrm{H}^{+}\right]\left[\mathrm{L}^{2-}\right] /\left[\mathrm{HL}^{-}\right]
\end{aligned}
$$

Ion association of $\alpha$-PAN-4S anions with $\mathrm{TBA}^{+}$in the aqueous phase:

$$
\begin{aligned}
& \mathrm{Q}^{+}+\mathrm{HL}^{-} \rightleftharpoons\left(\mathrm{Q}^{+} \mathrm{HL}^{-}\right) ; K_{\mathrm{f}, \mathrm{HL}}=\left[\mathrm{Q}^{+} \mathrm{HL}^{-}\right] /\left[\mathrm{Q}^{+}\right]\left[\mathrm{HL}^{-}\right] \\
& \mathrm{Q}^{+}+\mathrm{L}^{2-} \rightleftharpoons\left(\mathrm{Q}^{+} \mathrm{L}^{2-}\right)^{-} ; K_{\mathrm{f}, \mathrm{L}}=\left[\left(\mathrm{Q}^{+} \mathrm{L}^{2-}\right)^{-}\right] /\left[\mathrm{Q}^{+}\right]\left[\mathrm{L}^{2-}\right] \\
& \mathrm{Q}^{+}+\left(\mathrm{Q}^{+} \mathrm{L}^{2-}\right)^{-} \rightleftharpoons\left(\left(\mathrm{Q}^{+}\right)_{2} \mathrm{~L}^{2-}\right) ; \\
& K_{\mathrm{f}, \mathrm{L}}=\left[\left(\mathrm{Q}^{+}\right)_{2} \mathrm{~L}^{2-}\right] /\left[\mathrm{Q}^{+}\right]\left[\left(\mathrm{Q}^{+} \mathrm{L}^{2-}\right)^{-}\right],
\end{aligned}
$$

where $\mathrm{Q}^{+}$denotes the tetrabutylammonium ion. Partition of the ion associates:

$$
\left(\mathrm{Q}^{+} \mathrm{HL}^{-}\right) \rightleftharpoons\left(\mathrm{Q}^{+} \mathrm{HL}^{-}\right)_{0} ; K_{\mathrm{D},(\mathrm{QHL})}=\left[\mathrm{Q}^{+} \mathrm{HL}^{-}\right]_{\mathrm{o}} /\left[\mathrm{Q}^{+} \mathrm{HL}^{-}\right]
$$

$$
\begin{aligned}
\left(\left(\mathrm{Q}^{+}\right)_{2} \mathrm{~L}^{2-}\right) & \rightleftharpoons\left(\left(\mathrm{Q}^{+}\right)_{2} \mathrm{~L}^{2-}\right)_{\mathrm{o}} ; \\
K_{\mathrm{D},(\mathrm{Q} 2 \mathrm{~L})} & =\left[\left(\mathrm{Q}^{+}\right)_{2} \mathrm{~L}^{2-}\right]_{\mathrm{o}} /\left[\left(\mathrm{Q}^{+}\right)_{2} \mathrm{~L}^{2-}\right]
\end{aligned}
$$

where the subscript o refers to the organic phase.

The partition ratio of $\alpha-\mathrm{PAN}-4 \mathrm{~S}$ in the present systems can be written as

$$
D_{\mathrm{L}}=\frac{\left[\mathrm{Q}^{+} \mathrm{HL}^{-}\right]_{\mathrm{o}}+\left[\left(\mathrm{Q}^{+}\right)_{2} \mathrm{~L}^{2-}\right]_{\mathrm{o}}}{\left[\mathrm{HL}^{-}\right]+\left[\mathrm{Q}^{+} \mathrm{HL}^{-}\right]+\left[\mathrm{L}^{2-}\right]+\left[\left(\mathrm{Q}^{+} \mathrm{L}^{2-}\right)^{-}\right]+\left[\left(\mathrm{Q}^{+}\right)_{2} \mathrm{~L}^{2-}\right]}
$$

Taking into account the acid dissociation constants $\left(\mathrm{p} K_{\mathrm{al}}=2.80 \text { and } \mathrm{p} K_{\mathrm{a} 2}=7.95\right)^{12}$, the partition ratio of $\alpha$ $\mathrm{PAN}-4 \mathrm{~S}$ at $\mathrm{pH}=4$ can be approximated by

$$
D_{\mathrm{L}}=\frac{K_{\mathrm{D},(\mathrm{QHL})} K_{\mathrm{f}, \mathrm{HL}}\left[\mathrm{Q}^{+}\right]}{1+K_{\mathrm{f}, \mathrm{HL}}\left[\mathrm{Q}^{+}\right]}
$$

From Eq. (9) the following relation can be obtained:

$$
\begin{aligned}
& \log \left[\mathrm{Q}^{+}\right]-\log D_{\mathrm{L}}+\log K_{\mathrm{D},(\mathrm{QHL})}+\log K_{\mathrm{f}, \mathrm{HL}} \\
& \quad=\log \left(1+K_{\mathrm{f}, \mathrm{HL}}\left[\mathrm{Q}^{+}\right]\right)
\end{aligned}
$$

If the left-hand side of Eq. $(10)=Y$ and $K_{\mathrm{f}, \mathrm{HL}}\left[\mathrm{Q}^{+}\right]=X$, the equation is equivalent to $Y=\log (1+X)$. Then, according to Eq. (10), plots of $\log \left[\mathrm{Q}^{+}\right]-\log D_{\mathrm{L}}$ against $\log \left[\mathrm{Q}^{+}\right]$ should be superimposable on the normalized curve, $\log (1+X) v s . \log X$, and the values of $K_{\mathrm{D},(\mathrm{Q}, \mathrm{HL})}$ and $K_{\mathrm{f}, \mathrm{HL}}$ can be estimated from the respective deviations of the ordinate and abscissa between the plots and the normalized curve. The results for the mixed solvent having a mixing ratio of $1: 1$ are shown in Fig. 1 . The value of the constant is summarized in Table 1 together with constants for the other octane/1-octanol mixed solvents in mixing ratios of $2: 1$ and $3: 1$.

On the other hand, from Eq. (8) the partition ratio of $\alpha-\mathrm{PAN}-4 \mathrm{~S}$ at $\mathrm{pH}=12$ can be approximated by 


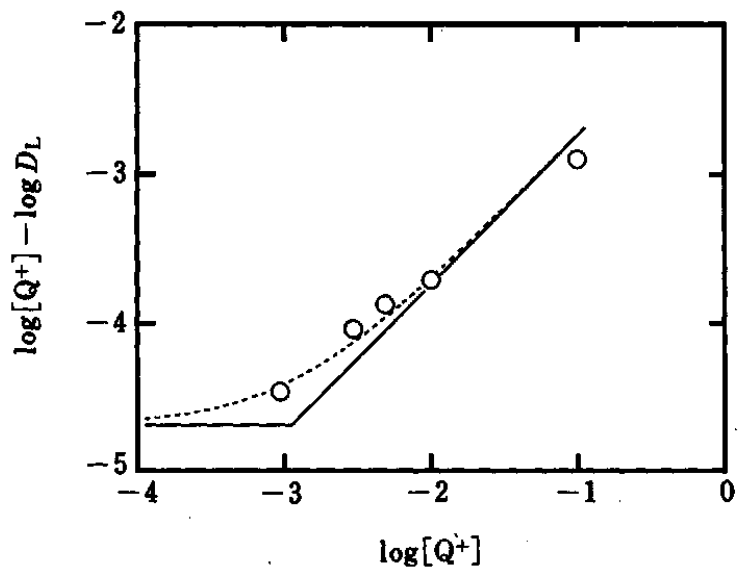

Fig. 1 Determination of the ion association and partition constants of HL: with $\mathrm{TBA}^{+}$. The dotted curve is the normalized curve, $\log (1+X)$ vs. $\log X$, and the solid lines are the asymptotes of the normalized curve. Extraction was carried out under the condition $C_{\alpha-\mathrm{PAN}-4 \mathrm{~S}}=7.0 \times 10^{-5} \mathrm{~mol}$ $\mathrm{dm}^{-3}$ and $\mathrm{pH}$ in the aqueous phase $\simeq 4$. The plots correspond to the octane/1-octanol mixed solvent in a volume ratio of $1: 1$.

$$
D_{\mathrm{L}}=\frac{K_{\mathrm{D},(\mathrm{Q} 2 \mathrm{~L})} K_{\mathrm{f} 1, \mathrm{~L}} K_{\mathrm{f}, \mathrm{L}}\left[\mathrm{Q}^{+}\right]^{2}}{1+K_{\mathrm{fl}, \mathrm{L}}\left[\mathrm{Q}^{+}\right]+K_{\mathrm{f}, \mathrm{L}} K_{\mathrm{f}, \mathrm{L}}\left[\mathrm{Q}^{+}\right]^{2}}
$$

Under the condition $\left[\mathrm{L}^{2-}\right]+\left[\left(\mathrm{Q}^{+} \mathrm{L}^{2-}\right)^{-}\right] \gg\left[\left(\mathrm{Q}^{+}\right)_{2} \mathrm{~L}^{2-}\right]$ in the aqueous phase, the above equation can be further approximated as

$$
D_{\mathrm{L}}=\frac{K_{\mathrm{D},(\mathrm{Q} 2 \mathrm{~L})} K_{\mathrm{f} 1, \mathrm{~L}} K_{\mathrm{f}, \mathrm{L}}\left[\mathrm{Q}^{+}\right]^{2}}{1+K_{\mathrm{fl}, \mathrm{L}}\left[\mathrm{Q}^{+}\right]}
$$

The following expression can be derived from Eq. (12):

$$
\begin{aligned}
& 2 \log \left[\mathrm{Q}^{+}\right]-\log D_{\mathrm{L}}+\log K_{\mathrm{D},(\mathrm{Q} 2 \mathrm{~L})}+\log K_{\mathrm{f} 1, \mathrm{~L}}+\log K_{\mathrm{f}, \mathrm{L}} \\
& \quad=\log \left(1+K_{\mathrm{f} 1, \mathrm{~L}}\left[\mathrm{Q}^{+}\right]\right)
\end{aligned}
$$

In a similar manner as in the case of Eq. (10), Eq. (13) is equivalent to $Y=\log (1+X)$. Then, on the basis of Eq. (13), by fitting plots of $2 \log \left[\mathrm{Q}^{+}\right]-\log D_{\mathrm{L}}$ against $\log \left[\mathrm{Q}^{+}\right]$ with the normalized curve, $\log (1+X)$ vs. $\log X$ as shown in Fig. 2, the values of $K_{\mathrm{f} 1, \mathrm{~L}}$ and the product of $K_{\mathrm{D},(\mathrm{Q} 2 \mathrm{~L})}$ and $K_{f 2, \mathrm{~L}}$ can be estimated, as given in Table 1 .

The value of $K_{\mathrm{fl}, \mathrm{L}}$ determined by the present work is comparable to the ion association constants $\left(\log K_{\text {ass }}=\right.$ 1.6-1.8) of four kinds of anionic divalent azo dyes similar to $\alpha$-PAN-4S, with the tetrabutylammonium ion, which were recently determined by capillary zone electrophoresis by Motomizu et al. ${ }^{13}$

As can be seen in Fig. 2, the plots for the 2:1 and 3:1 mixed solvents deviate upward from the normalized curve with increasing $\left[\mathrm{TBA}^{+}\right]$. This suggests that the species $\left(\left(\mathrm{Q}^{+}\right)_{2} \mathrm{~L}^{2-}\right)$ cannot be neglected in the aqueous phase. In this region the relation $\left[\mathrm{L}^{2-}\right] \ll\left[\left(\mathrm{Q}^{+} \mathrm{L}^{2-}\right)^{-}\right]+$ $\left[\left(\mathrm{Q}^{+}\right)_{2} \mathrm{~L}^{2-}\right]$ can be expected to be established for the

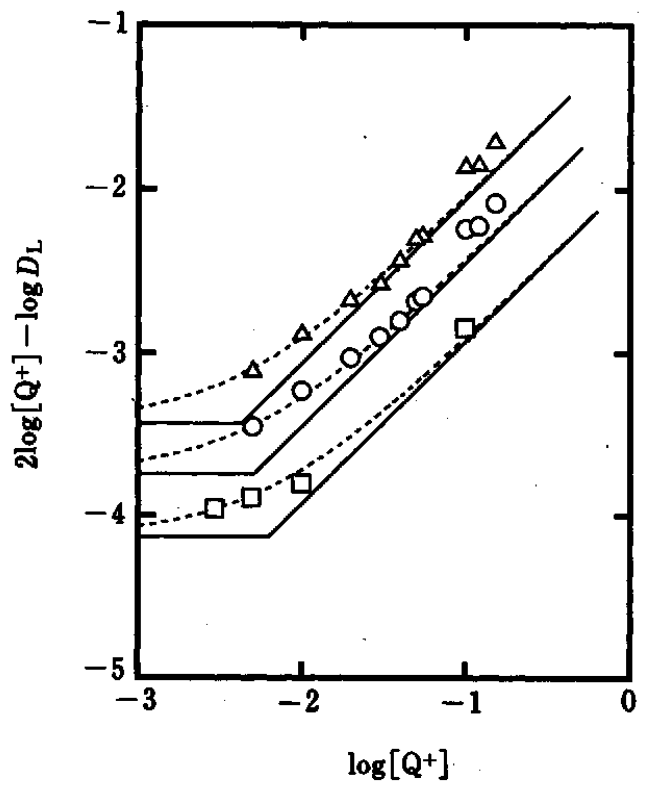

Fig. 2 Determination of the ion association constant of $\mathrm{L}^{2-}$ with $\mathrm{TBA}^{+}$. The dotted curves and solid lines are the same as in Fig: 1. Symbols: $\triangle, O$ and $\square$ denote the octane/1octanol mixed solvents in volume ratios of $3: 1,2: 1$ and $1: 1$, respectively. Extraction was carried out under the condition $C_{\alpha-\mathrm{PAN}-4 \mathrm{~S}}=7.0 \times 10^{-5} \mathrm{~mol} \mathrm{dm}^{-3}$ and $\mathrm{pH}$ in the aqueous phase $\simeq 12$.

Table 1 Ion association and partition constants of $\alpha$-PAN4S anions with tetrabutylammonium cation

\begin{tabular}{lccc}
\hline \multirow{2}{*}{ Constant } & \multicolumn{3}{c}{ Mixing ratio (octane : 1 -octanol (v/v)) } \\
\cline { 2 - 4 } & $1: 1$ & $2: 1$ & $3: 1$ \\
\hline $\log K_{\mathrm{f}, \mathrm{HL}}$ & 2.9 & 2.3 & 2.0 \\
$\log K_{\mathrm{f} 1, \mathrm{~L}}$ & 2.2 & 2.3 & 2.4 \\
$\log K_{\mathrm{f}, \mathrm{L}}$ & $(0.5)$ & 0.5 & 0.5 \\
$\log K_{\mathrm{D},(\mathrm{Q}, \mathrm{HL})}$ & 1.74 & 1.50 & 1.24 \\
$\log K_{\mathrm{D},(\mathrm{Q} 2, \mathrm{~L})}$ & $(1.43)$ & 0.96 & 0.56 \\
\hline $\log \left(K_{\mathrm{D},(\mathrm{Q} 2, \mathrm{~L})} \cdot K_{\mathrm{f}, \mathrm{L}}\right)$ & 1.93 & 1.46 & 1.06 \\
\hline
\end{tabular}

concentration of the $\alpha$-PAN-4S species in the aqueous phase. Under this condition, the following expression can be approximated from Eq. (11):

$$
D_{\mathrm{L}}=\frac{K_{\mathrm{D},(\mathrm{Q} 2 \mathrm{~L})} K_{\mathrm{f}, \mathrm{L}}\left[\mathrm{Q}^{+}\right]}{1+K_{\mathrm{f}, \mathrm{L}}\left[\mathrm{Q}^{+}\right]}
$$

From Eq. (14) the following equation can be obtained:

$$
\begin{aligned}
& \log \left[\mathrm{Q}^{+}\right]-\log D_{\mathrm{L}}+\log K_{\mathrm{D},(\mathrm{Q} 2 \mathrm{~L})}+\log K_{\mathrm{f} 2, \mathrm{~L}} \\
& \quad=\log \left(1+K_{\mathrm{f}, \mathrm{L}}\left[\mathrm{Q}^{+}\right]\right) .
\end{aligned}
$$

In a similar manner as Eq. (10), plots of $\log \left[\mathrm{Q}^{+}\right]-\log D_{\mathrm{L}}$ against $\log \left[\mathrm{Q}^{+}\right]$and the normalized curve, $\log (1+X)$ vs. 


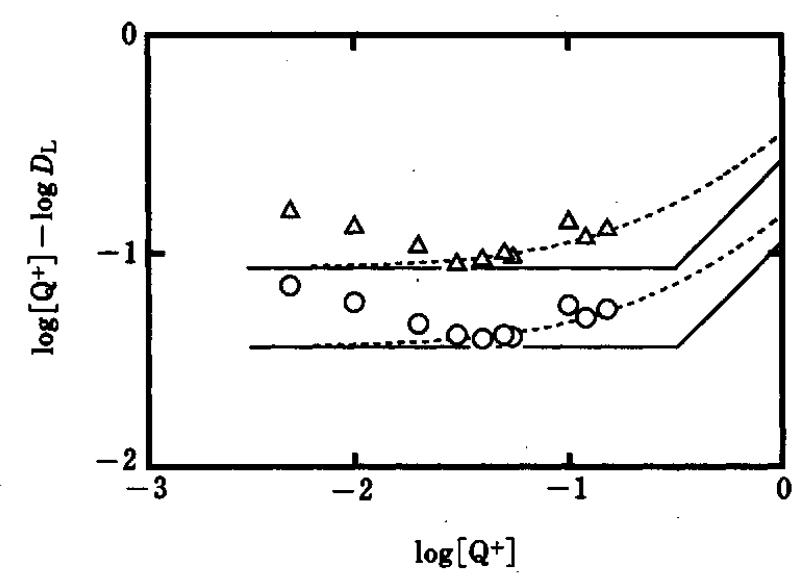

Fig. 3 Determination of the ion association and partition constants of $\left(\mathrm{TBA}^{+}, \mathrm{L}^{2-}\right)^{-}$with $\mathrm{TBA}^{+}$. The curves, lines, symbols and the extraction conditions are the same as in Fig. 2.

$\log X$ can be superposed upon each other, and the values of $K_{\mathrm{D},(\mathrm{Q} 2 \mathrm{~L})}$ and $K_{\mathrm{f}, \mathrm{L}}$ can be estimated. The results for mixed solvents in a mixing ratios of $2: 1$ and 3:1 are shown in Fig. 3 and the values of the constants are summarized in Table 1 together with other constants. In a system using the $1: 1$ mixed solvent, the results under the region: $\left[\mathrm{L}^{2-}\right] \ll\left[\left(\mathrm{Q}^{+} \mathrm{L}^{2-}\right)^{-}\right]+\left[\left(\mathrm{Q}^{+}\right)_{2} \mathrm{~L}^{2-}\right]$ could not be obtained, as shown in Fig. 2. In this case, the ion association constant of $\left(\left(\mathrm{Q}^{+}\right)_{2} \mathrm{~L}^{2-}\right)$ in the aqueous phase can be expected to be equal to the value of the constant for the 2:1 and 3:1 mixed solvents, since the ion association constant in the aqueous phase should be independent of the organic phase; that is, $K_{\mathrm{fL}}$ can be regarded as $\log K_{\mathrm{f}, \mathrm{L}}=0.5$. Then, the partition constant of $\left(\left(\mathrm{Q}^{+}\right)_{2} \mathrm{~L}^{2-}\right)$ can be calculated from the values of $\left(K_{\mathrm{D},(\mathrm{Q} 2 \mathrm{~L})} \cdot K_{\mathrm{f} 2, \mathrm{~L}}\right), K_{\mathrm{fl}, \mathrm{L}}$ and $K_{\mathrm{f} 2, \mathrm{~L}}$ according to Eq. (13). The values are listed in parentheses in Table 1.

For an analysis of these partition equilibria, it is necessary to know the concentration of $\left[\mathrm{TBA}^{+}\right]$in the aqueous phase. In the present conditions, as $\mathrm{TBA}^{+}$is added in large excess for $\alpha-\mathrm{PAN}-4 \mathrm{~S}$, we adopted $\left[\mathrm{TBA}^{+}\right]=$the total concentration of the tetrabutylammonium ion, $\left(C_{\mathrm{TBA}}\right)$ as a first approximation. The values of the ion association constants and the partition constants of ion associates obtained from the first approximation as $\left[\mathrm{TBA}^{+}\right]=C_{\mathrm{TBA}}$ were in agreement with those reevaluated from plots against $\left[\mathrm{TBA}^{+}\right]$, which was calculated by employing the ion association and partition constants obtained on the basis of $\left[\mathrm{TBA}^{+}\right]=C_{\mathrm{TBA}}$. Then, it was found that $\left[\mathrm{TBA}^{+}\right]$can be approximated to $C_{\mathrm{TBA}}$ under the present experimental conditions.

Partition of ion associate of $\mathrm{CuL}_{2}{ }^{2-}$ with tetrabutylammonium ion

The effects of the pH and the concentration of $\alpha-P A N-$ $4 \mathrm{~S}$ on the partition ratio of copper(II) are shown in Figs. 4 and 5, respectively. As can be seen in Fig. 4, the partition ratio of copper(II) increases with the $\mathrm{pH}$,

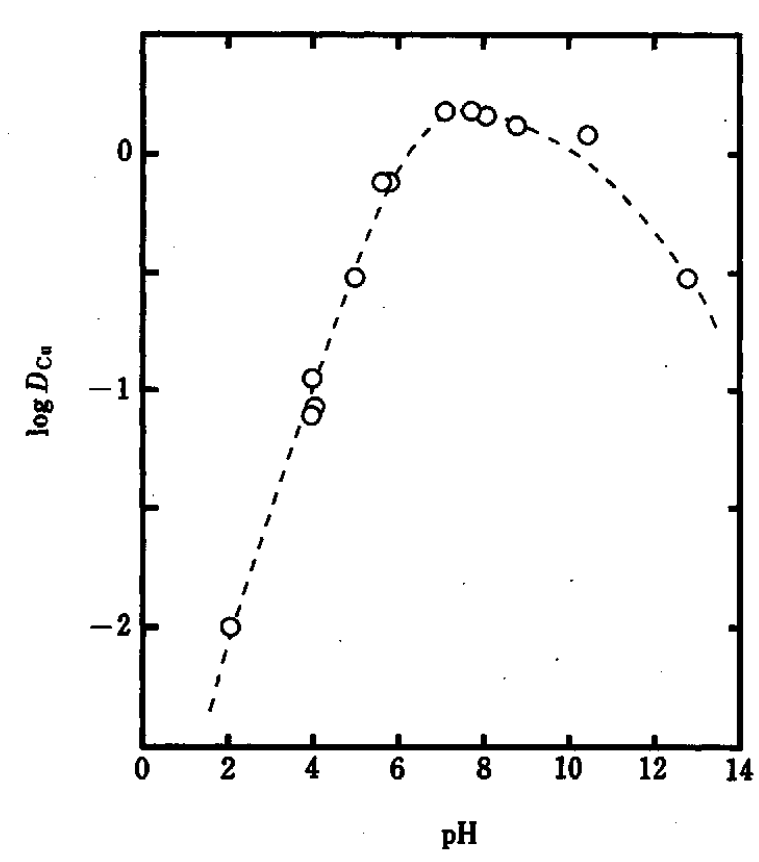

Fig. 4 Effect of the pH on the extraction of copper(II) with $\alpha-P A N-4 S$ and $\mathrm{TBA}^{+}$. The conditions: $C_{\mathrm{Cu}}=1.0 \times 10^{-5}$, $C_{\alpha-\mathrm{PAN}-\mathrm{AS}}=7: 0 \times 10^{-5}$ and $C_{\mathrm{TBA}}=1.0 \times 10^{-2} \mathrm{~mol} \mathrm{dm}^{-3}$, respectively.

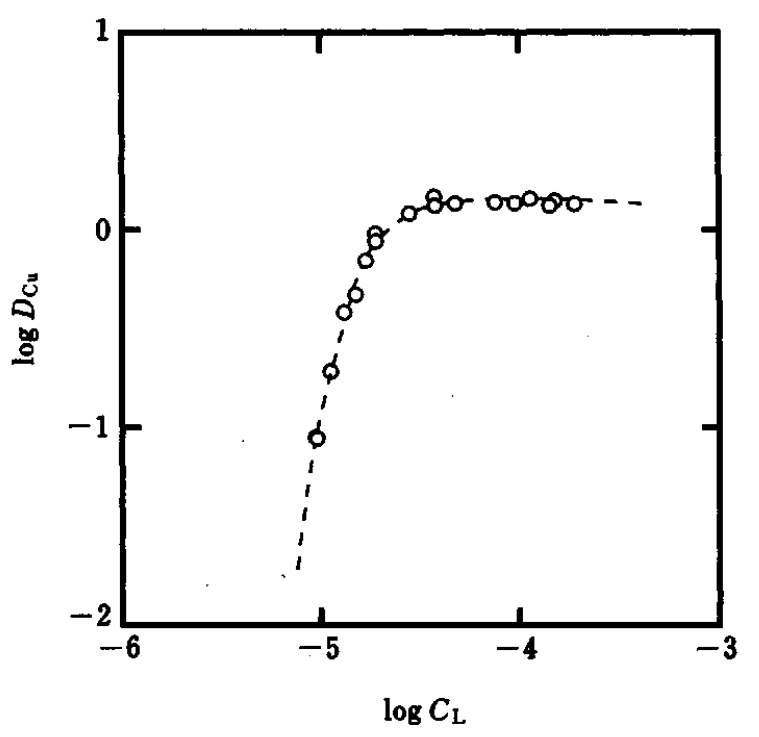

Fig. 5 Effect of the concentration of $\alpha$-PAN-4S on the extraction of copper(II) with $\alpha-\mathrm{PAN}-4 \mathrm{~S}$ and TBA ${ }^{+} . \quad C_{\mathrm{Cu}}$ and $C_{\mathrm{TBA}}$ are the same as in Fig. 4 , and $\mathrm{pH}$ in the aqueous phase $\approx 8$.

and is kept constant at $\mathbf{p H}=7-8$. It begins to decrease in $\mathrm{pH}$ to more than 8 . Taking into account this $\mathrm{pH}$ dependence and $\mathrm{p} K_{\mathrm{a} 2}$ of $\alpha-\mathrm{PAN}-4 \mathrm{~S}$, the extraction of copper(II) with $\alpha$-PAN-4S and TBA $^{+}$was decided to be carried out while keeping the $\mathrm{pH}$ at about 8 . The partition ratio of copper(II) was found to remain 
constant at a concentration of $\alpha-\mathrm{PAN}-4 \mathrm{~S}$ of more than $4 \times 10^{-5} \mathrm{~mol} \mathrm{dm}^{-3}$ under the present extraction conditions, as shown in Fig. 5. In these regions the copper(II) species in both the aqueous and organic phases can be expected to involve in the same number of $\alpha-\mathrm{PAN}-4 \mathrm{~S}$; that is, copper(II) can be anticipated to quantitatively form $\mathrm{CuL}_{2}{ }^{2-}$.

Then, the partition ratio of copper(II) under the conditions in $C_{\mathrm{Cu}}=1 \times 10^{-5} \mathrm{~mol} \mathrm{dm}^{-3}, C_{\alpha-\mathrm{PAN}-\mathrm{SS}}=7 \times 10^{-5} \mathrm{~mol}$ $\mathrm{dm}^{-3}$ and $\mathrm{pH}$ in the aqueous phase $=8$ can be written as

$$
\begin{aligned}
D_{\mathrm{Cu}} & =\frac{\left[\left(\mathrm{TBA}^{+}\right)_{2} \mathrm{CuL}_{2}{ }^{2-}\right]_{\mathrm{o}}}{\left[\mathrm{CuL}_{2}{ }^{2-}\right]+\left[\left(\mathrm{TBA}^{+} \mathrm{CuL}_{2}{ }^{2-}\right)^{-}\right]+\left[\left(\mathrm{TBA}^{+}\right)_{2} \mathrm{CuL}_{2}{ }^{2-}\right]} \\
& =\frac{K_{\mathrm{D},(\mathrm{Q} 2 \mathrm{CuL} 2)} K_{\mathrm{f} 1, \mathrm{CuL} 2} K_{\mathrm{f}, \mathrm{CuL} 2}\left[\mathrm{Q}^{+}\right]^{2}}{1+K_{\mathrm{f} 1, \mathrm{CuL} 2}\left[\mathrm{Q}^{+}\right]+K_{\mathrm{f} 1, \mathrm{CuL} 2} K_{\mathrm{f}, \mathrm{CuL} 2}\left[\mathrm{Q}^{+}\right]^{2}}
\end{aligned}
$$

where $K_{\mathrm{D},(\mathrm{Q} 2 \mathrm{CuL} 2),} K_{\mathrm{fl}, \mathrm{CuL} 2}$ and $K_{\mathrm{fz}, \mathrm{CuL} 2}$ denote the partition constant and stepwise ion association constants of the ion associates, respectively, and can be represented as follows:

$$
\begin{aligned}
& \mathrm{TBA}^{+}+\mathrm{CuL}_{2}{ }^{2-} \rightleftharpoons\left(\mathrm{TBA}^{+} \mathrm{CuL}_{2}{ }^{2-}\right)^{-} ; \\
& K_{\mathrm{fl}, \mathrm{CuL} 2}=\left[\left(\mathrm{Q}^{+} \mathrm{CuL}_{2} 2^{2-}\right)^{-}\right] /\left[\mathrm{Q}^{+}\right]\left[\mathrm{CuL}_{2}{ }^{2-}\right] \\
& \mathrm{TBA}^{+}+\left(\mathrm{TBA}^{+} \mathrm{CuL}_{2}{ }^{2-}\right)^{-} \rightleftharpoons\left(\left(\mathrm{TBA}^{+}\right)_{2} \mathrm{CuL}_{2}{ }^{2-}\right) ; \\
& \left.K_{\mathrm{f} 2, \mathrm{CuL} 2}=\left[\left(\mathrm{Q}^{+}\right)_{2} \mathrm{CuL}_{2}{ }^{2-}\right)^{-}\right] /\left[\mathrm{Q}^{+}\right]\left[\left(\mathrm{Q}^{+} \mathrm{CuL}_{2}{ }^{2-}\right)^{-}\right], \\
& \left(\left(\mathrm{TBA}^{+}\right)_{2} \mathrm{CuL}_{2}{ }^{2-}\right) \rightleftharpoons\left(\left(\mathrm{TBA}^{+}\right)_{2} \mathrm{CuL}_{2}{ }^{2-}\right)_{0} ; \\
& K_{\mathrm{D},(\mathrm{Q} 2 \mathrm{CuL} 2)}=\left[\left(\mathrm{Q}^{+}\right)_{2} \mathrm{CuL}_{2}{ }^{2-}\right]_{\mathrm{o}} /\left[\left(\mathrm{Q}^{+}\right)_{2} \mathrm{CuL}_{2}{ }^{2-}\right] .
\end{aligned}
$$

Under the condition $\left[\mathrm{CuL}_{2}{ }^{2-}\right]+\left[\left(\mathrm{Q}^{+} \mathrm{CuL}_{2}{ }^{2-}\right)^{-}\right] \gg$ $\left[\left(\mathrm{Q}^{+}\right)_{2} \mathrm{CuL}_{2}{ }^{2-}\right]$, the partition ratio of copper(II) can be approximated by

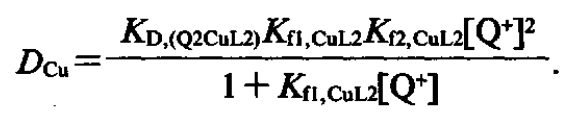

In addition, the following equation can be derived from Eq. (20):

$$
\begin{aligned}
& 2 \log \left[\mathrm{Q}^{+}\right]-\log D_{\mathrm{Cu}}+\log K_{\mathrm{D},(\mathrm{Q} 2 \mathrm{CuL} 2)}+\log K_{\mathrm{f} 1 \mathrm{CuL} 2} \\
& +\log K_{\mathrm{f}, \mathrm{CuL} 2}=\log \left(1+K_{\mathrm{f} 1, \mathrm{CuL} 2}\left[\mathrm{Q}^{+}\right]\right)
\end{aligned}
$$

Analogously to the case of Eq. (10) described above, by fitting plots of $2 \log \left[\mathrm{Q}^{+}\right]-\log D_{\mathrm{Cu}}$ against $\log \left[\mathrm{Q}^{+}\right]$with the normalized curve, $\log (1+X) v s . \log X$, the constant of $K_{\mathrm{fl}, \mathrm{CuL2} 2}$ and the product of $K_{\mathrm{D},(\mathrm{Q} 2 \mathrm{CuL} 2)}$ and $K_{\mathrm{R}, \mathrm{CuL} 2 \mathrm{c}}$ can be estimated. As can be seen in Fig. 6, the plots and the normalized curve were superposed upon each other in the lower concentration range of $\mathrm{TBA}^{+}$. The ion association constant ( $K_{\mathrm{f} 1, \mathrm{CuL} 2)}$ and the product of $K_{\mathrm{D},(\mathrm{Q} 2 \mathrm{CuL} 2)}$ and $K_{\mathrm{f} 2, \mathrm{CuL} 2}$ were obtained in a similar manner as above. The values are summarized in Table 1.

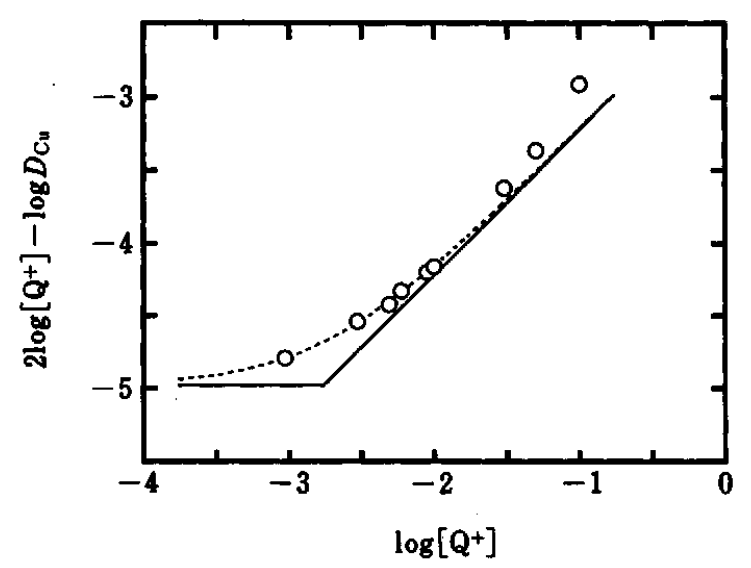

Fig. 6 Determination of the ion association constant of $\mathrm{CuL}_{2}{ }^{2-}$ with $\mathrm{TBA}^{+}$. The dotted curves and solid lines are the same as in Fig. 1. The conditions: $C_{\mathrm{Cu}}=1.0 \times 10^{-5}$, $C_{\alpha-\mathrm{PAN}-4 \mathrm{~S}}=7.0 \times 10^{-5} \mathrm{~mol} \mathrm{dm}^{-3}$ and $\mathrm{pH}$ in the aqueous phase $\approx 8$, respectively. The plots correspond to the octane/1-octanol mixed solvent in a volume ratio of $1: 1$.

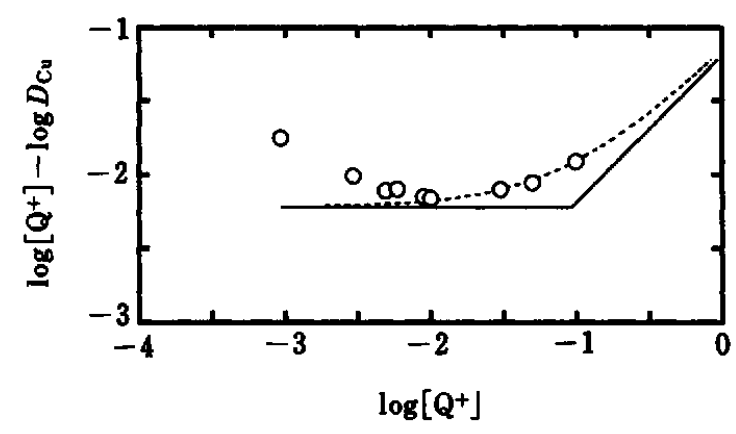

Fig. 7 Determination of the ion association constant of $\left(\mathrm{TBA}^{+} \mathrm{CuL}_{2}{ }^{2-}\right)^{-}$with $\mathrm{TBA}^{+}$and the partition constant of the ion associate, $\left(\left(\mathrm{TBA}^{+}\right)_{2} \mathrm{CuL}_{2}{ }^{2-}\right)$. The curves and lines are the same as in Fig. 1. The conditions are the same as in Fig. 6.

When the relation $\left[\mathrm{CuL}_{2}^{2-}\right] \ll\left[\left(\mathrm{Q}^{+} \mathrm{CuL}_{2}{ }^{2-}\right)^{-}\right]+$ $\left[\left(\mathrm{Q}^{+}\right)_{2} \mathrm{CuL}_{2}{ }^{2-}\right]$ can be expected to hold, the following expressions can be derived from Eq. (16):

$$
D_{\mathrm{Cu}}=\frac{K_{\mathrm{D},(\mathrm{Q} 2 \mathrm{CuL}, 2)} K_{\mathrm{r}, \mathrm{CuL} 2}\left[\mathrm{Q}^{+}\right]}{1+K_{\mathrm{f}, \mathrm{CuL} 2}\left[\mathrm{Q}^{+}\right]},
$$

and

$$
\begin{aligned}
& \log \left[\mathrm{Q}^{+}\right]-\log D_{\mathrm{Cu}}+\log K_{\mathrm{D},(\mathrm{Q} 2 \mathrm{CuL} 2)}+\log K_{\mathrm{f}, \mathrm{CuL} 2} \\
& \quad=\log \left(1+K_{\mathrm{r}, \mathrm{CuL} 2}\left[\mathrm{Q}^{+}\right]\right) .
\end{aligned}
$$

Plots for the extraction system using a 1:1 mixed solvent on the basis of Eq. (23) are shown in Fig. 7 in a similar manner as above. The plots fit well with the normalized curve under the higher concentration of $\mathrm{TBA}^{+}$. The 
Table 2 Ion association and partition constants of ion associates $\mathrm{CuL}_{2}{ }^{2-}$ with $\mathrm{TBA}^{+}$

\begin{tabular}{lccc}
\hline \multirow{2}{*}{ Constant } & \multicolumn{3}{c}{ Mixing ratio (octane : 1-octanol (v/v)) } \\
\cline { 2 - 4 } & $1: 1$ & $2: 1$ & \multicolumn{1}{c}{$3: 1$} \\
\hline $\log K_{\mathrm{fl},(\mathrm{Q}, \mathrm{CuL} 2)}$ & 2.76 & 2.68 & 2.70 \\
$\log K_{\mathrm{f} 2,(\mathrm{Q} 2, \mathrm{CuL} 2)}$ & 1.03 & 1.17 & 1.55 \\
$\log K_{\mathrm{D},(\mathrm{Q} 2, \mathrm{CuL} 2)}$ & 1.19 & 0.17 & -0.72 \\
\hline
\end{tabular}

values of $K_{\mathrm{f}, \mathrm{CuL} 2}$ and $K_{\mathrm{D},(\mathrm{Q} 2 \mathrm{CuL} 2)}$ can be determined from the respective deviations of the coordinates between the plots and the normalized curve. The value of $\left(K_{12, \mathrm{CuL2}}{ }^{\circ}\right.$ $\left.K_{\mathrm{D},(\mathrm{Q} 2 \mathrm{CuL} 2)}\right)$ obtained from Fig. 7 is consistent with the value from Fig. 6 described above.

It is necessary to estimate the concentration of free tetrabutylammonium ion in the aqueous phase in order to analyze these extraction equilibria as well as to analyze the partition equilibrium of $\alpha$-PAN-4S with the tetrabutylammonium ion described above. Taking into account the results of the partition equilibrium of $\alpha$ PAN-4S with TBA ${ }^{+}$and the presence of a large excess of $\mathrm{TBA}^{+}$to copper(II), plots based on Eq. (23) were carried out against the total concentration of $\mathrm{TBA}^{+}$, that is, $\left[\mathrm{TBA}^{+}\right]=C_{\mathrm{TBA}}$ as a first approximation. Subsequently, the ion association constants and the partition constants were determined from plots against $\left[\mathrm{TBA}^{+}\right]$calculated using the constants obtained by the first approximation. These second values of the respective constants differed slightly from the first values on the basis of $\left[\mathrm{TBA}^{+}\right]=$ $C_{\mathrm{TBA}}$. The third values of the respective constants obtained by repeating the same method descrived above were in agreement with the values estimated by the second analysis. Then, these values were regarded as being the respective constants. The values are summarized in Table 2 together with the constants determined for the other mixed solvent systems by the same method as in the 1:1 mixed solvent system. In Figs. 6 and 7 the results for the third analysis are plotted.

In Fig. 8 the calculated curves on the basis of Eq. (16) are drawn using the results obtained by the present study. The curves fit well with the observed values for the every mixed solvent, and the validity of the present results is supported.

\section{Solvent effect on the partition equilibrium of ion associates}

According to the regular solution theory ${ }^{14-16}$, the partition constant of a solute (A) can be expressed as

$$
\frac{\log K_{\mathrm{D}, \mathrm{A}}}{\delta_{\mathrm{w}}-\delta_{\mathrm{o}}}=\frac{V_{\mathrm{A}}}{2.30 R T}\left(\delta_{\mathrm{o}}^{\prime}+\delta_{\mathrm{w}}-2 \delta_{\mathrm{A}}\right)
$$

with

$$
\delta_{\mathrm{o}}^{\prime}=\delta_{\mathrm{o}}+\frac{R T}{\delta_{\mathrm{w}}-\delta_{\mathrm{o}}}\left(\frac{1}{V_{\mathrm{o}}}-\frac{1}{V_{\mathrm{w}}}\right)
$$

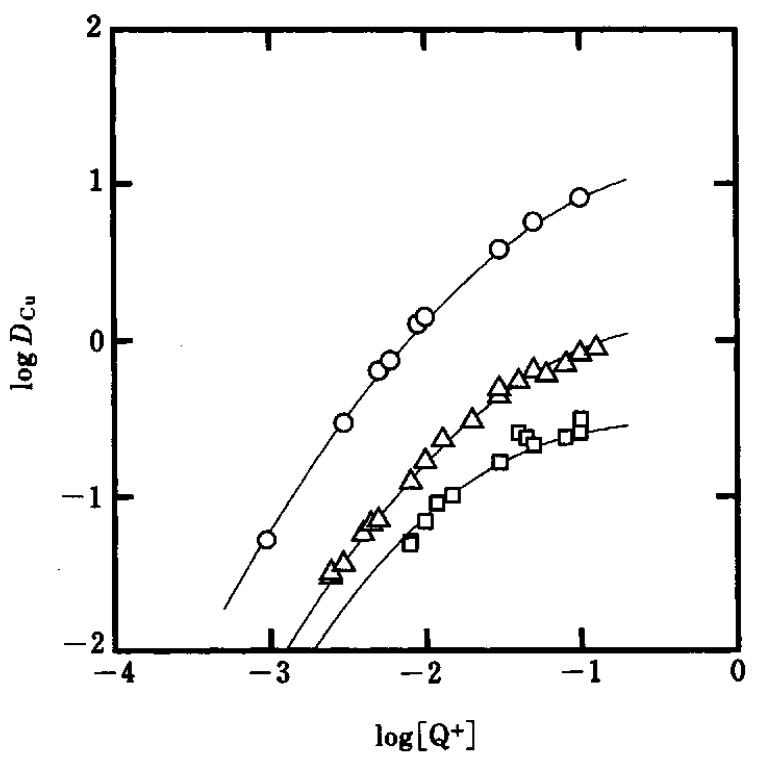

Fig. 8 Comparison of the experimental values with the calculated curves based on the results obtained in the present study. The solid curves are the calculated ones. Symbols: $O, \Delta$ and $\square$ denote the octane/1-octanol mixed solvents in volume ratios of $1: 1,2: 1$ and $3: 1$, respectively.

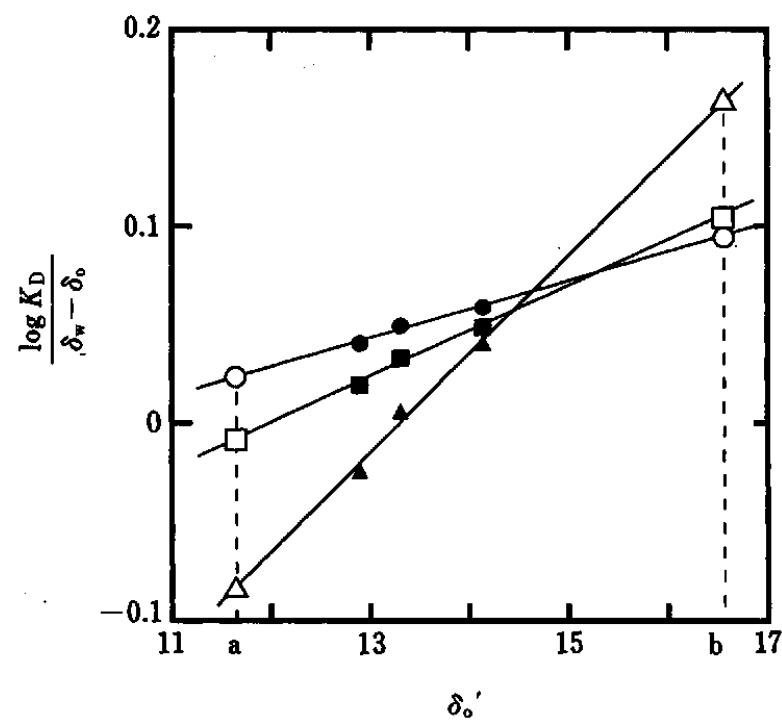

Fig. 9 Estimation of the partition constants of three kinds of ion associates according to the regular solution theory. The symbols $\boldsymbol{\square} \square$ and $\Delta$ refer to the respective ion associates, $\left(\mathrm{TBA}^{+} \mathrm{HL}^{-}\right),\left(\left(\mathrm{TBA}^{+}\right)_{2} \mathrm{~L}^{2-}\right)$ and $\left(\left(\mathrm{TBA}^{+}\right)_{2} \mathrm{CuL}_{2}{ }^{2-}\right)$, respectively. Points $a$ and $b$ refer to the respective $\delta_{0}{ }^{\prime}$ for pure octane and 1-octanol, respectively.

where $K_{\mathrm{D}}, \delta$ and $V$ denote the partition constant, the solubility parameter and the molar volume, and subscripts $A, O$ and $w$ refer to the solute, organic solvent and water, respectively.

On the basis of Eq. (24), a linear relationship between the left-hand side of Eq. (24) and $\delta_{0}{ }^{\prime}$ can be expected to be 
Table 3 Partition constants of ion associates for the pure octane and 1-octanol systems

\begin{tabular}{lrc}
\hline \multicolumn{1}{c}{ Constant } & Octane & 1-Octanol \\
\hline $\log K_{\mathrm{D},(\mathrm{Q}, \mathrm{HL})}$ & 0.74 & 2.54 \\
$\log K_{\mathrm{D},(\mathrm{Q} 2, \mathrm{~L})}$ & -0.27 & 2.81 \\
$\log K_{\mathrm{D},(\mathrm{Q}, \mathrm{CuL} 2)}$ & -2.73 & 4.40 \\
\hline
\end{tabular}

established. Plots of the left-hand side of the equation against $\delta_{0}^{\prime}$ for three kinds of ion associates, $\left(\mathrm{Q}^{+} \mathrm{HL}^{-}\right)$, $\left(\left(\mathrm{Q}^{+}\right)_{2} \mathrm{~L}^{2-}\right)$ and $\left(\left(\mathrm{Q}^{+}\right)_{2} \mathrm{CuL}_{2}{ }^{2-}\right)$ are shown in Fig. 9, respectively. The solubility parameter of the mixed solvents were calculated by the following expression: ${ }^{17}$

$$
\delta_{\operatorname{mix}}=\frac{\phi_{1} \delta_{1}+\phi_{2} \delta_{2}}{\phi_{1}+\phi_{2}}
$$

where $\phi$ denotes the volume fraction and subscripts 1 and 2 refer to octane and 1-octanol, respectively. Although the linearity of the plots was observed for the respective ion associates, the molar volume of each ion associate calculated from the slope of the respective straight line was found to be considerably smaller than the value expected from the molar volume of each ion. By extrapolating of the respective straight lines for each ion associate to the values of $\delta_{0}{ }^{\prime}$ for pure octane and 1 octanol ( $a$ and $b$ in Fig. 9), the partition constants of the respective ion associates in the extraction systems using pure octane and 1-octanol as a solvent can be estimated. The values are summarized in Table 3. As can be seen in Table 3, the poor extractability of octane for copper(II) was found to be attributable to the extreme small partition constant of $\left(\left(\mathrm{Q}^{+}\right)_{2} \mathrm{CuL}_{2}{ }^{2-}\right)$. In the 1-octanol system, this constant is larger by about seven orders of magnitude than in the octane system. It is possible to prepare a solvent which possesses any extractability between 1-octanol and octane by controlling the mixing ratio of these both extreme solvents for the extractability.

The partition constants of the respective ion associates decrease in the order $\left(\left(\mathrm{Q}^{+}\right)_{2} \mathrm{CuL}_{2}{ }^{2-}\right)>\left(\left(\mathrm{Q}^{+}\right)_{2} \mathrm{~L}^{2-}\right)>\left(\mathrm{Q}^{+} \mathrm{HL}^{-}\right)$ in the 1-octanol system, but are just the opposite order in the octane system. This difference can be attributed to the structure of the ion associates, the polarity and solvating ability of the solvent. However, an additional investigation is required to elucidate these problems.

The present work was supported by a Grant-in-Aid for Scientific Research (No. 08455388) from the Ministry of Education, Science, Sports and Culture.

\section{References}

1. S. Motomizu, S. Hamada and K. Toei, Bunseki Kagaku, 32, 648 (1983).

2. S. Motomizu, S. Hamada and K. Toei, Bunseki Kagaku, 32, 703 (1983).

3. S. Motomizu, Bunseki Kagaku, 33, 31 (1984).

4. S. Motomizu, Bumseki Kagaku, 38, 147 (1989).

5. S. Taguchi, K. Nakamura, T. Hiraide and K. Goto, Bunseki Kagaku, 31, 548 (1982).

6. K. Goto, S. Taguchi, H. Miyabe and K. Haruyama, Bunseki Kagaku, 32, 678 (1983).

7. I. Kasahara, Y. Ohgaki, K. Matui, K. Sano, S. Taguchi and K. Goto, Nippon Kagaku Kaishi, 1986, 894.

8. H. Matunaga and T. Yotsuyanagi, Nippon Kagaku Kaishi, $1982,785$.

9. H. Yamada, K. Yajima, Y. Noda and H. Wada, Anal. Sci., 12, 419 (1996).

10. R. G. Anderson and G. Nickless, Analyst [London], 93, 13 (1968).

11. H. Yamada, K. Yajima, H. Wada and G. Nakagawa, Talanta, 42, 789 (1995).

12. K. Ohshita, H. Wada and G. Nakagawa, Anal. Chim. Acta, 140, 291 (1982).

13. T. Takayanagi, H. Tanaka and S. Motomizu, Anal. Sci., 13, 11 (1997).

14. T. Wakahayashi, S. Oki, T. Omori and N. Suzuki, $J$. Inorg. Nucl. Chem., 26, 2255 (1964).

15. I. Kojima, M. Yoshida and M. Tanaka, J. Inorg. Nucl. Chem., 32, 987 (1970).

16. H. Yamada and M. Tanaka, J. Inorg. Nucl. Chem., 38, 1501 (1976).

17. J. H. Hildebrand, J. M. Prausnitz and R. L. Scott, "Regular and Related Solutions", p.149, Van Nostrand Reinhold, New York, 1970.

(Received March 21, 1997)

(Accepted May 26, 1997) 